\title{
Influence of balancing holes and disc sealing in turbine stages on thermodynamic efficiency and rotor forces
}

\author{
Václav Sláma ${ }^{1, a}$ \\ ${ }^{1} R \& D$ Specialist Sciences, Thermodynamics Department, Doosan Škoda Power s.r.o., Tylova 1/57, 30128 Plzeň, Czech Republic
}

\begin{abstract}
This paper deals with CFD analysis of a particular turbine impulse stage including the surrounding parts such as diaphragm seals, shroud seals and a disc axial gap, where balancing holes and a disc sealing is designed. The aim is to investigate effects on efficiency and axial forces by evaluation of a pressure distribution on the rotor disc and respective mass flow balances. As a result of this, the possible methodology of design optimization could be found. The other part of the project is to find the way for a more exact preliminary computation which is essential for increasing efficiency and the reduction of the axial forces.
\end{abstract}

\section{Introduction}

\subsection{Motivation}

An increasing of efficiency is the main challenge for each research and development department in the companies of power engineering. Although a lot of significant improvements have been made such as the development of blade profiles or the optimization of exhaust hoods, there are still many possibilities how the efficiency can be increased. One of them is a reduction of the negative influence of steam which cannot produce an output because it does not flow through blade cascades (nozzles and buckets), where the output is produced, but through the surrounding parts such as diaphragm seals or shroud seals. Owing to construction requirements, a small but not insignificant amount of the steam always has to go through these parts. We can reduce this amount, but never completely. An approach how to estimate this mass flow and possibilities of the reduction is described, for example, in reference 1 . The rest of this steam should be used in an appropriate way so as not to disturb the main flow.

In addition, it is very desirable to find ways how to decrease the turbine price. For example the price could be decreased by using optimal bearings whose size determines construction costs. If the influence of the particular turbine parts on the flow phenomena is known, it could allow us to estimate an axial force in the rotor. Accordingly, it is possible to use smaller bearings which could be considerably cheaper.

The mentioned possibility of increasing the efficiency and the accurate estimation of forces is closely dependent on the turbine sections around a rotor disc. By using a CFD analysis, which is described in this paper, the influence of important construction parts in the rotor disc have been identified and described. The results have been implemented in a homemade loss model and have also been considered during a standard design procedure.

\subsection{Wheel stage design}

One of the widely used designs for turbine stages is a wheel stage design which is shown in figure 1. It was created particularly for impulse stages but the similar principle could be used in various modern stages.

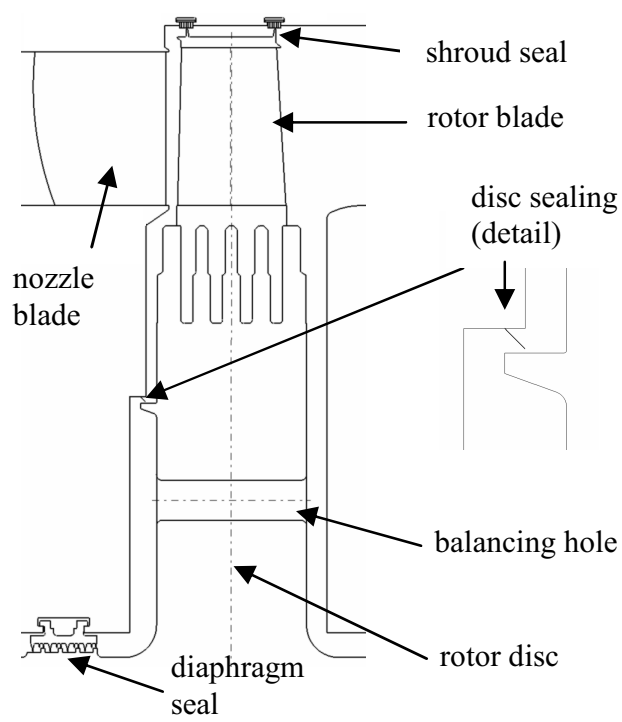

Figure 1. Typical wheel stage design.

In figure 1, are shown typical parts of all turbine stages the nozzle and the rotor blade and the diaphragm and the shroud seal. There are also the parts which are specifically in the wheel stage design - the balancing

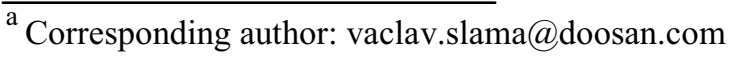


hole and the disc sealing. These two parts are main subjects of this study.

\subsubsection{Balancing hole}

One purpose of the balancing hole is to allow the steam going from the diaphragm seal to flow through the rotor disc to the next turbine stage so that this steam would not be mixed with the main flow upstream of the rotor blades. This mixing produces losses because the direction of the steam going through the diaphragm seal and adjacent rotor disc parts is different from the direction of the steam going from the stator blades. These losses are often included into the secondary losses. A lot of detailed researches and studies have been carried out. (For examples see references 2, 3 and 4). On the whole, the balancing holes could significantly increase the efficiency. Another purpose of using the balancing holes is to decrease an axial force in the rotor. This effect is sometimes considered to be more important than the efficiency increasing.

\subsubsection{Disc sealing}

The other typical construction part in the wheel stage designs is the disc sealing. It usually consists of a thin strip which is situated against the rotor part (it can be seen in detail in figure 1). The main purpose of the disc sealing is to decrease the amount of steam going from the cascade. This effect is described in detail in the results section. As a consequence, it helps to increase the efficiency. On the other hand, by using the disc sealing the axial force could increase.

\section{Computational model}

\subsection{Domains and meshes}

A package of ANSYS tools was used for carrying out the CFD analysis. Turbo Grid 15.0 was used for creating meshes of the rotor and the stator domain while ICEM 15.0 was used for other domains, where a blocking strategy was largely used. An appropriate boundary layer was used so that an average value of $y+$ would be lower than 1 .

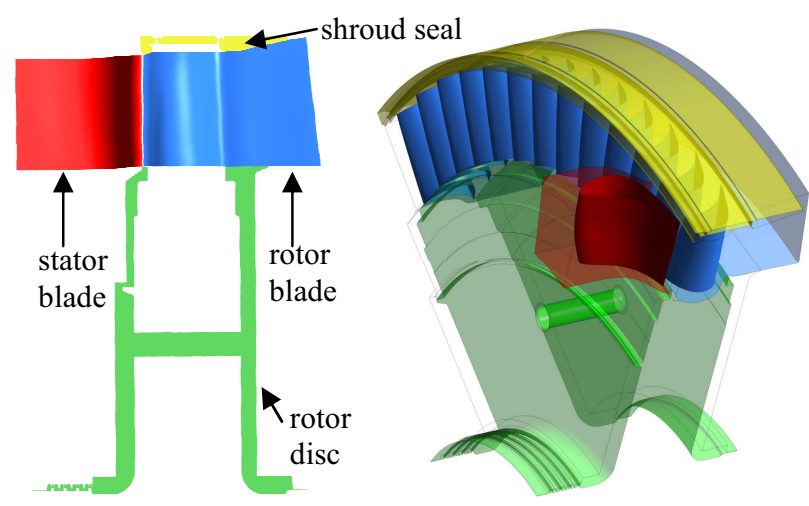

Figure 2. Computation model.
The used model, which is depicted in figure 2, consists of four domains. The number of rotor blades had to be adjusted according to the balancing hole (there are thirteen blades for one hole) so that flow phenomena could be simulated correctly in the rotor disc part.

What is more, because we need to compare the influence of the mentioned parts, the model was adapted so that the balancing hole and the disc sealing could or could not be used. Thanks to this, four variants could be computed and the influence of each observed part could be described. The names of the variants are in table 1 .

Table 1. Used variants.

\begin{tabular}{|c|c|c|}
\hline name & balancing hole & disc sealing \\
\hline A & no & no \\
\hline B & no & yes \\
\hline C & yes & no \\
\hline D & yes & yes \\
\hline
\end{tabular}

\subsection{Numerical solution and boundary conditions}

A numerical solver CFX 15.0 was chosen as the main CFD software tool. A numerical computation using the steady state RANS analysis was performed by using a compressible turbulent flow with the k- $\omega$ SST turbulent model. The medium was considered as a real gas.

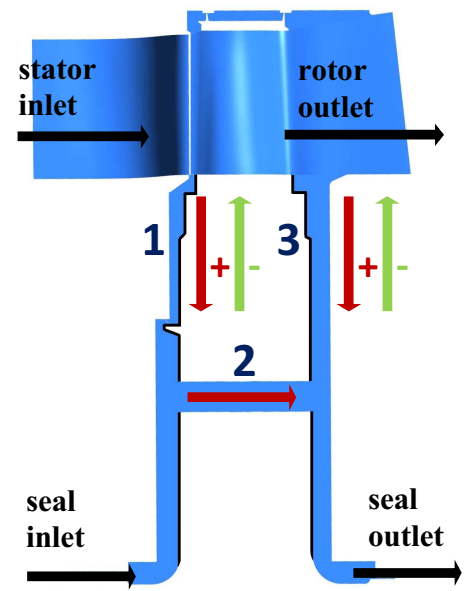

Figure 3. Boundary conditions and monitoring places.

Boundary conditions with the flow directions are shown in figure 3. A total pressure and temperature distribution as well as a flow direction was defined at the stator inlet and an average static pressure with a radial equilibrium condition was defined at the rotor outlet. A total pressure according to the computed mass flow was defined at the seal inlet and a mass flow outlet was defined at the seal outlet (there is in fact an inlet to the diaphragm seal of the next turbine stage). Rotational periodicity conditions were applied to corresponding free side boundaries of the computation domains. Connections between the domains were defined as interfaces which were specified as a stage or a frozen rotor.

\subsection{Monitored parameters}

Due to the fact that the analysis is very complex, many parameters had to be monitored during the computation 
in order to check that the solution was converged enough. The monitored parameters were mass flow balances, axial forces acting to parts connected with the rotor (the rotor disc, the rotor blades and the shroud seal) and static pressure distributions on rotor disc surfaces.

The mass flows were monitored especially in the rotor disc part (defined as 1, 2 and 3 sections in figure 3 ). The monitoring of mass flow balances through the other parts, which are the shroud seal, the stator inlet and the rotor outlet were carried out too, but these results are not important for our further evaluations. The pressure distribution was monitored on the disc surfaces (this surface is represented by the bold black line in figure 3). The inlet part of the disc as well as the outlet part was considered. The other essential monitored parameter was the stage efficiency which was evaluated as total to total.

\section{Results}

As was mentioned before, the computations of four different models, which differ in either having the balancing hole and the disc sealing or not, were carried out. According to the preliminary assumptions, the results are strongly dependent on the computed variant.

\subsection{Efficiency and axial forces}

The following graphs in figure 4 present the comparison of the efficiency and of the axial rotor force.
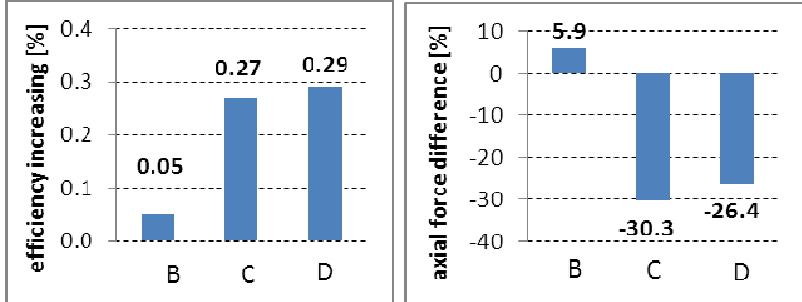

Figure 4. Efficiency and forces comparison.

If we compare the variants where there is the balancing hole $(\mathrm{C}$ and $\mathrm{D})$ with the variants without the hole (A and B), the positive effect can be seen. The efficiency was increased by about $0.3 \%$. In addition, the force was significantly reduced by about $30 \%$. The effect of the disc sealing (the difference between 0.29 and 0.27 ) seems to be negligible but in the wider terms each increment of the efficiency is very desirable. The other fact is that this increment should be significantly greater in other turbine stages.

\subsection{Mass flow balances}

A reason why the balancing hole considerably influences the efficiency can be explained by comparing the mass flows which are in table 2 (the evaluating positions of the flows 1, 2 and 3 were described in figure 3 ). In this picture, we can also see plus and minus directions. If the steam goes from the cascade to the adjacent rotor disc part, the direction is positive because this effect increases the efficiency. On the contrary, the minus direction means that the flow goes to the cascade which has a negative effect. The optimal is when the mass flow through the part 1 is very closed to zero but this case can hardly be reached in practice. The greater the leakage going from the cascade, the greater losses are produced. For this reason, the disc sealing is commonly used. However, the positive effect is not always too substantial. Although the difference of the mass flow between the variants $C$ and $D$ is at about $0.3 \mathrm{~kg} \mathrm{~s}^{-1}$, the efficiency was increased only by $0.02 \%$. This result shows that if we want to increase the efficiency, we need to reduce the leakage more significantly. In a practical way, it can for example mean to design a smaller clearance in the disc sealing.

Table 2. Mass flows through observed parts (in $\mathrm{kg} \mathrm{s}^{-1}$ ).

\begin{tabular}{|c|c|c|c|}
\hline name & flow 1 & flow 2 & flow 3 \\
\hline A & -1.217 & - & 0.867 \\
\hline B & -1.217 & - & 0.867 \\
\hline C & 0.902 & 2.119 & -1.252 \\
\hline D & 0.507 & 1.781 & -0.914 \\
\hline
\end{tabular}

Regarding the facts mentioned before, it seems to be not difficult to generalize that by using balancing holes and disc sealing is always of benefit in each turbine impulse stage. However, the influence of the disc sealing is small in this study. In addition, the question as to how significant is the increase in efficiency has to be answered for future using because the accurate estimation of the efficiency is very important. Therefore, many other detailed studies, including CFD, and experiments have been done. See references 4 and 5. As a result, a homemade efficiency prediction procedure has been considerably increased.

\subsection{Pressure distribution}

pressure distribution on the outlet part of the disc pressure distribution on

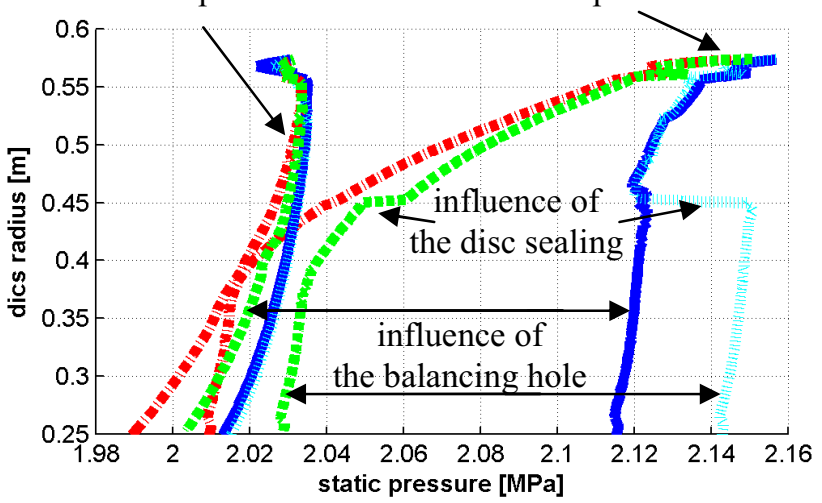

\footnotetext{
A - without hole and without sealing

$B$ - without hole and with sealing

moln $C$ - with hole and without sealing numun D - with hole and with sealing
}

Figure 5. Pressure distribution on the disc.

The pressure distribution on the disc for each variant is depicted in figure 5. An understanding of these 
distributions is essential for an axial forces estimation. There can be clearly seen the influence of the balancing holes as well as the influence of the disc sealing.

The significant pressure difference between the variants with the balancing holes (C and D) and the variants without the balancing holes (A and $\mathrm{B}$ ) shows the important impact of the holes. We would like to avoid having the big pressures which are in the variants $\mathrm{A}$ and B. Therefore, the balancing holes should be used in order to have the lower axial force in the rotor. The pressure is the lowest in the variant $\mathrm{C}$ where the pressure on the inlet disc part is almost the same as in the outlet disc part, particularly in the middle section where the balancing hole is situated. It is the best solution regarding the axial forces but in order to increase the efficiency the disc sealing is used. Its effect can be visible as horizontal parts in the variants of B and D, where the pressure is sharply changed. It means that if the disc sealing is added, the pressure difference between the inlet and outlet part is greater which shows the disc sealing impact that is not desirable. Fortunately, this pressure increase, which is in fact the axial force increase, is not as significant as the impact of the balancing hole.

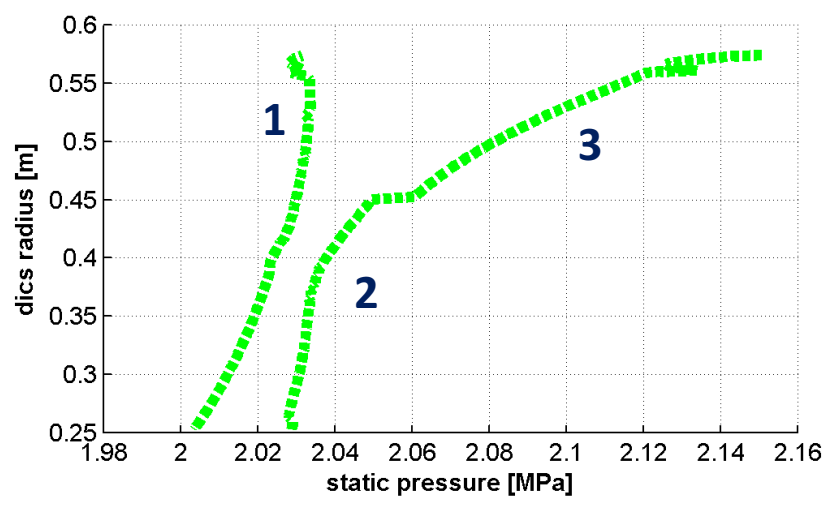

Figure 6. Pressure distribution on the disc in the variant D.

The result of the pressure distribution of $\mathrm{D}$ variant is used in this paper to briefly describe how to deal with the generalisation of results. This generalization is essential owing to the fact that it is absolutely not economic to use CFD for computing each turbine stage which one is going to design. As it was said, the estimation of the pressure distribution on the disc is vital for computing the rotor axial force. In order to create this estimation, we can use general equations of flow in the disc (see reference 6) and add the particular coefficients according to the knowledge from CFD computations.

As is shown in figure 6, the pressure distribution is not linear. It is caused by the influence of whirls, rotor revolutions and the amount of steam going through the rotor disc parts. As we can see, the curve could be divided into different parts. While the pressure distribution on the outlet part of the disc could be described as one curve, the pressure distribution on the inlet part has to be described by two curves at least. As a result, the final estimation of the pressure distribution could be defined as a function of the revolutions, a radial position, a clearance between rotor and stator parts, mass flow through the relevant parts and pressures and temperatures at the rotor hub as well as in the seals. In addition, this function has to be multiplied by the coefficients which are different according to the position on the disc (1, 2 or 3 in figure 6$)$.

As we can imagine, the computed coefficients are dependent on a turbine design, therefore they would be different for variant turbine stages. It means that the different values, which have been either computed or estimated, have to be used during the stage design procedure. For this reason, not only the turbine stage presented here was computed but also some experiments have been carried out.

\section{Conclusion and further work}

The numerical analysis of the flow phenomena in the rotor disc section representing the wheel stage design has provided general and valuable information about the dependence of the balancing holes and the disc sealing on the efficiency and the axial force in a rotor. It was clearly shown that the balancing holes have considerable effect on increasing the efficiency and in reducing the axial force. The influence of the disc sealing was also described by using the comparison of mass flow balances.

The importance was placed on the analysis of the pressure distribution on the rotor disc. It was said that the static pressure distribution could be described as dependent on the basic stage parameters and by using the appropriate partition of the showed pressure distribution curves.

The results, which were presented in this paper, have been used as the references for similar computations and for the improvement of the current prediction of the efficiency and for the estimation of the axial force in the rotor. This endeavour leads to the fact that the efficiency of a steam turbine can be improved and the production costs can be reduced by using a modernised estimation computational approach.

\section{References}

1. V. Sláma, P. Epikaridis, V. Vaník, M. Hajšman: Study of Mass Flow in Steam Turbine Labyrinth Seals. $\left(29^{\text {th }}\right.$ Conference of Computational Mechanics, Špičák 2013)

2. L. Bednář, M. Hoznedl, L. Tajč: Účinnost turbinových stup̌̌u III. upravené vydání. (Doosan Škoda Power, Plzeň 2010)

3. M. Hoznedl, J. Linhart, L. Tajč: Vliv vefukování do mezní vrstvy na ztrátový součinitel výstupního hrdla. (pp. 53-56, Praha 2006)

4. V. Sláma, L. Tajč, K. Yun: Vliv hř́delové ucpávkové páry na účinnost turbínového stupně. (Turbostroje, Praha 2015)

5. K. Yun, L. Tajč: Vliv geometrických úprav oběžných lopatek a prívodního kanálu pro páru z hř́delové ucpávky na aerodynamické parametry proudu páry. (Doosan Škoda Power, Plzeň 2014)

6. A. V. Ščegljajev: Parní turbíny 1. Svazek. (SNTL, Praha 1983) 